\title{
On the Validation of the Passion Scale in Chinese
}

\author{
Yaxi Zhao ${ }^{{ }^{*}}$, Ariane St-Louis ${ }^{2}$ and Robert J Vallerand ${ }^{2}$
}

\author{
${ }^{*}$ Correspondence: \\ zhaoyaxi@mail2.sysu.edu.cn \\ ${ }^{1}$ Department of Psychology, \\ Sun Yat-Sen University, \\ 132 Daxuecheng Outer Ring \\ East Rd, Panyu Guangzhou, \\ Guangdong 510006, China \\ Full list of author information \\ is available at the end of the \\ article
}

\begin{abstract}
The Dualistic Model of Passion posits the existence of two types of passion, namely harmonious and obsessive passion. These two types of passion have been assessed through the Passion Scale. This scale has been validated in French and English and translated in several languages. The purpose of the present research was to translate and validate it in Chinese. To this end, 286 Chinese university students completed an online questionnaire in Chinese that contained the Passion Scale, the passion criteria, as well as measures of flow and positive and negative affect. Results provided support for the two-factor structure of the Passion Scale in Chinese and for the high reliability for both subscales $\left(\alpha_{H P}=0.86 ; \alpha_{O P}=0.82\right)$. Furthermore, correlations between the harmonious and obsessive passion subscales and the passion criteria and flow and affect scales supported the convergent and divergent validity of the Chinese Passion Scale. Overall, these findings suggest that the Passion scale can be used in future research with Chinese participants.
\end{abstract}

Keywords: Passion, Scale, Confirmatory factor analysis (CFA), Reliability, Convergent and divergent validity

\section{Background}

A lot of research has been conducted worldwide on the concept of passion using the Dualistic Model of Passion and the Passion Scale (see Vallerand 2008, 2010, 2015, for reviews). Although passion has been celebrated in all cultures, most of the contemporary research on passion has been conducted in the Western culture (see Vallerand 2015). Vallerand and colleagues initially created the Passion Scale in 2003 (originally the scale was developed in French) and provided strong support for the psychometric properties of the scale. The Passion Scale was later refined and validated with over 3,500 men and women from the Western culture (Marsh et al. 2013). The Passion Scale was also found equivalent both in the French and English languages. Over the years, the factorial and construct validity of the Passion Scale has been validated in more than 20 studies (see Vallerand 2015 for a review). In addition, the scale has been translated in several other languages such as Russian, Hungarian, and Spanish, and the research findings are consistent with those from the Western culture (see Vallerand 2015 for reviews). In line with the above, passion would appear to represent a construct that is generalizable to other cultures, including the Chinese culture.

(c) 2015 Zhao et al. This article is distributed under the terms of the Creative Commons Attribution 4.0 International License (http:// creativecommons.org/licenses/by/4.0/), which permits unrestricted use, distribution, and reproduction in any medium, provided you give appropriate credit to the original author(s) and the source, provide a link to the Creative Commons license, and indicate if changes were made. 
In order to conduct such research in the Eastern culture and specifically in China, it would be important to validate the Passion Scale in Chinese. Although some studies on passion have been conducted with Chinese participants (e.g. Burke et al. 2014; Liu et al. 2011; Wang and Chu 2007), such research has either used the earlier version of the Passion Scale (Vallerand et al. 2003) or has not fully tested the psychometric properties of the scale. Thus, research on the validation of the refined version of the Passion Scale (Marsh et al. 2013) in Chinese is necessary.

\section{The Dualistic Model of Passion}

The Dualistic Model of Passion defines passion as "a strong inclination toward a specific object, activity, concept or person that one loves (or at least strongly likes) and highly values, that is part of identity, and that leads one to invest time and energy in the activity on a regular basis" (Vallerand 2015). Passion can enhance well-being, provide motivation, and fuel self-fulfilment in life. However, passion can also induce negative emotions, lead to inflexible persistence, and undermine well-being. To account for the fact that passion can lead to either positive and negative outcomes, the dualistic model proposes the existence of two distinct type of passion: harmonious passion (HP) and obsessive passion (OP), which can be discriminated by how passion is internalized into one's identity. According to self-determination theory (SDT), internalization is the process in which people transform socially sanctioned values and behaviours into individuals either in an autonomous or a controlled way (Deci and Ryan 2000). Such process is likely to take place when those values and behaviours are highly valued, meaningful, and feel like chosen by us (Deci et al. 1994). When the internalization is autonomous, people appraise principles as important, assimilate them into identity of their own will, and therefore fully turn them into their own. Otherwise, people are forced to accept these principles, and then the principles may be only partially internalized into ones' identity or even stay external (Marsh et al. 2013). In line with the SDT, Vallerand et al. (2003) proposed that these two types of internalization should take an important role in the development of passion and these processes should result in HP and OP, respectively.

Taking origin from an autonomous internalization, HP is a strong desire to freely engage in the activity. Thus, the source of passion is integrated into one's self-structure (Hodgins and Knee 2002). Therefore, albeit the passion occupies a significant role in the person's identity, it is in coherence with other parts of him/her. People with predominant harmonious passion should present an open and non-defensive attitude toward the passionate activity (Hodgins and Knee 2002), and consequently should experience positive outcomes during the activity (e.g., positive emotions, flow).

On the contrary, OP results from a controlled internalization and refers to an uncontrollable urge to partake in the favourite activity. In this case, people internalize not only the activity, but also some contingencies attached to it. Thus, individuals with OP would develop ego-invested self-structures and show more defensiveness toward what is happening within the activity (Hodgins and Knee 2002). As a result, individuals with a predominant OP would be less likely to experience flow and other positive outcomes during the activity. Furthermore, they may even experience negative outcomes, such as negative emotions. 
As an example of the distinction between HP and OP toward studies, people with a predominant HP are highly invested in their studies yet very flexible in terms of their engagement. Specifically, even though they spend a lot of time and energy in their studies, they manage to balance their engagement with other life domains such as relationships, friendships, work, etc. Furthermore, they experience positive emotions such as feeling active and alert during and after engaging in their studies. Conversely, individuals with a predominant OP for their studies are also highly invested in them but they can't help but to engage in their studies. Their studies become the core of their lives, thus creating much conflict with other important aspects of life that are often being neglected. People with an OP for their studies do experience positive emotions when engaging in their studies but to a lesser extent than individuals with an HP and they unfortunately experience negative emotions such as feeling nervous and guilty during and after engaging in their studies.

Over 100 empirical studies have supported the Dualistic Model of Passion and at least 20 have provided support for the psychometric properties of the Passion Scale, including its two-factor solution, using exploratory and confirmatory factor analysis and exploratory structure equation modelling in various life domains and several languages (e.g. Carbonneau et al. 2008; Gousse-Lessard et al. 2013; Marsh et al. 2013; OrgambídezRamos et al. 2014; see Vallerand 2010, 2015 for a review). In addition, all studies including those in laboratory settings, showed high levels of internal consistency for both types of passion, with Cronbach $\alpha$ varying between 0.70 and 0.92 (e.g., Marsh et al. 2013; Stenseng 2008; Vallerand et al. 2003). Moreover, correlations between the two types of passion and the passion criteria (Marsh et al. 2013; Vallerand et al. 2003) and various outcomes (see Vallerand 2008, 2010, 2015, for reviews) have provided sufficient convergent and divergent validity. The passion criteria were developed based on the definition of passion (Vallerand et al. 2003). They refer to the extent to which the person likes or loves the activity, values it, spends a lot of time and energy on it, sees it part of him or herself, and subjectively believes that this activity is a passion for him or her. Research has shown that HP and OP are both positively related to the passion criteria (Marsh et al. 2013; Vallerand et al. 2003). In addition, past research on passion has looked at the relationships between passion and other related constructs such as flow and positive and negative emotions experienced during and outside the passionate activity. Findings reveals that HP is positively, whereas OP in most cases is either unrelated or even negatively correlated, with flow (e.g. Forest et al. 2011; Philippe et al. 2009, Study 1; Wang et al. 2011; see Vallerand 2010, 2015, for reviews), positive emotions (e.g. Philippe et al. 2010; Vallerand et al. 2003, 2006). Finally, HP is either unrelated or negatively related, whereas OP is positively related to negative emotions (e.g., Carbonneau et al. 2010, Study 1; Lafrenière et al. 2009; Young et al. 2014).

\section{The Present Research}

The purpose of the present research was to translate the refined version of the Passion Scale (Marsh et al. 2013) in Chinese and test its validity and reliability. To do so, we first translated the Passion Scale in Chinese using back-translation procedures (Vallerand 1989). After a pilot study suggesting that the Passion Scale in Chinese was acceptable, university students completed an online questionnaire. This questionnaire contained 
the Passion Scale toward one's studies, the passion criteria (for e.g. "my studies are passion for me"), as well as the level of flow and positive and negative emotions experienced when engaging in one's studies.

The present research had four main hypotheses. First, confirmatory factor analyses should support the two-factor structure of the Passion Scale in Chinese. Second, measurement invariance should be confirmed by multi-group comparisons between the Eastern (Chinese) and Western (Canada) cultures. Third, in order to assess convergent validity and because the passion criteria represent elements of the definition of passion discussed previously, we expected that both types of passion would be positively correlated with all criteria. Finally, divergent validity was assessed by looking at differences in relationship pattern between the two types of passion and three important related constructs (the experience of flow and positive and negative emotions during activity engagement). It was expected that HP would be positively related to flow and positive emotions, but negatively related or unrelated to negative emotions while OP would be positively related to negative emotions, but negatively or unrelated to positive emotions and flow.

\section{Methods}

\section{Participants}

The sample consisted of 286 Chinese university students. Two participants were eliminated from the analyses because they were outliers on the negative emotions variable (higher than 3 SD). Participants were 123 men, 160 women, and 3 unspecified; 203 of them were undergraduate students, 64 were Masters students, and 19 were Ph.D. candidates. Age ranged from 17 to 39 years $(M=22.23$ years, $S D=2.84$ years). Participants had been students for 16.3 years $(S D=2.49$ years). On average, students spent $34.69 \mathrm{~h}$ per week $(S D=22.47 \mathrm{~h})$ on their studies during the school year and $11.54 \mathrm{~h}$ per week $(S D=11.85 \mathrm{~h})$ when on holiday. Participants were reached through an online questionnaire sent by Email, Weibo, Facebook, and some instant chat software, which are publicly used in China. All participants accepted the consent form before responding to the questionnaire.

\section{Measures}

\section{Passion for One's Studies}

Passion for one's studies was measured using the refined Passion Scale (Marsh et al. 2013) in Chinese. The Chinese version of the Passion Scale was developed as indicated below in the procedures. In the Passion Scale, two six-item subscales assess harmonious passion and obsessive passion. Because the activity pertained to one's studies, the scale was adapted accordingly (e.g. "My studies are in harmony with other activities in my life"). Responses were given on a 7-point Likert scale from 1 (Not agree at all) to 7 (Very Strongly Agree). Cronbach alpha values for the HP and OP subscales were respectively 0.74 and 0.84 . Several studies have shown that students, especially college students, can be passionate for their studies (e.g., Stoeber et al. 2011; Vallerand et al. 2007, Study 2).

\section{Passion Criteria}

The criteria of passion for one's studies were assessed by five items $(\alpha=0.84)$, referring to time spent on the activity, liking the activity, valuing the activity, as well as passion and identity, respectively (see Table 5 in "Appendix" for the wording of the Passion Criteria). 
Flow

Flow experienced by students during their studies in general was assessed by the Chinese version of S-DFS (Short Dispositional Flow Scale; 刘 2010). This short scale contains nine items, using one item from each dimension of the full-length scale (Jackson and Eklund 2002; Jackson and Marsh 1996; Jackson et al. 2008). Because this scale was originally created to measure the experience of flow in sports, the item "I do things spontaneously and automatically without having to think" was removed. Indeed, spontaneous and automatic actions without thinking are unlikely to take place in one's studies. Thus, the S-DFS used in this study contained eight items, assessed on a 5-point Likert scale ranging from 1 (Never) to 5 (Always). The internal consistency of the scale in this study was 0.74 .

\section{Positive and Negative Emotions}

Positive and negative emotions experienced by students when engaging in their studies in general were assessed by the Chinese version of the Positive and Negative Affect Scale (邱 et al. 2008). This PANAS includes two nine-item subscales assessing positive emotions (e.g. cheerful; $\alpha=0.92$ ) and negative emotions (e.g. sad; $\alpha=0.88$ ). Responses were given on a 5-point Likert scale, from 1 (Very slightly/Not at all) to 5 (Very strongly).

\section{Procedures}

The first step was to translate the Passion Scale and the Passion Criteria (Marsh et al. 2013) into Chinese using the double back-translation technique (Vallerand 1989). All of the items and instruction of the Passion Scale and the Passion Criteria were first translated into Chinese by two translators independently, and then back-translated into English by another two translators, again independently. Subsequently, the four translators and Professor Vallerand discussed online to make sure that there were no meaning differences between the Chinese and English versions. All translators were fully bilingual in both English and Chinese. They were students in psychology who were explained the nature of the passion construct and the distinction between harmonious and obsessive passion. A thorough discussion of each item took place where the meaning of each item for the Chinese culture was scrutinized. Finally, a pilot study was conducted with seven Chinese students who completed the Chinese Passion Scale before conducting the actual online survey. None of the participants reported difficulties understanding the scale and when asked to explain the items, their responses were consistent with those of North American participants with the English version of the scale.

Once the Passion scale was translated into Chinese, we proceeded with data collection using an online survey. On the first page of the questionnaire, the purpose of the study and the consent form were presented. If participants consented to participation, then came the socio-demographic questions and the Passion Scale, the Passion Criteria, the S-DFS, and the PANAS scale.

\section{Results}

In order to test the validity and reliability of the Chinese Passion Scale, the following analyses were conducted. First, a CFA was carried out. Then, the internal consistency of the scale was established with the Cronbach alphas. Next, correlations between the 
Harmonious and Obsessive Passion subscales and the passion criteria were conducted. Finally, correlations were run between the two passion subscales and flow and positive and negative emotions.

\section{The Chinese Passion Scale Factor Structure: CFA}

Because the Passion Scale two-factor structure has been confirmed several times, a CFA was conducted ${ }^{\mathrm{a}}$ with MPlus 5.0 (Muthén and Muthén 2008-2011) using robust maximum-likelihood estimator (MLR) with standard errors and test of fit that are robust in relation to non-normality of observations (Marsh et al. 2013). The modification indices suggested that the inclusion of two correlated uniqueness would improve the fit (one between HP items 1 and 6, and the other between OP items 3 and 4; see Table 5 in "Appendix" for the wording of the items). With the inclusion of the correlated uniqueness, the fit of CFA solution was acceptable $(C F I=0.939$, TLI $=0.921$, RMSEA $=0.069)$. The factor loadings appear in Table 1 . All loadings were statistically significant and substantial. The correlation between HP and OP was 0.43 . These findings provide support for the factorial validity of the Passion Scale.

\section{Internal Consistency}

Cronbach alphas revealed that the internal consistency of both subscales of the Chinese Passion Scale was acceptable. Specifically, the reliability was 0.86 for HP and 0.82 for OP.

\section{Multigroup Tests of Measurement Invariance}

Multiple group tests of measurement invariance between representative samples of the Eastern and Western cultures were conducted in order to demonstrate psychometric

Table 1 Results from the confirmatory factor analysis

\begin{tabular}{lll}
\hline HP and OP items & Factor loadings & Uniq \\
\hline HP & & \\
My studies are in harmony with the other activities in my life (HP1) & 0.59 & $0.66^{\mathrm{a}}$ \\
The new things that I discover with my studies allow me to appreciate & 0.72 & 0.49 \\
$\quad$ it even more (HP2) & & 0.52 \\
My studies reflect the qualities I like about myself (HP3) & 0.69 & 0.43 \\
My studies allow me to live a variety of experiences (HP4) & 0.75 & 0.43 \\
My studies are well integrated in my life (HP5) & 0.75 & $0.57^{\mathrm{a}}$ \\
My studies are in harmony with other things that are part of me (HP6) & 0.66 & 0.51 \\
OP & & 0.47 \\
I have difficulties controlling my urge to do my studies (OP1) & 0.70 & $0.50^{\mathrm{b}}$ \\
I have almost an obsessive feeling for my studies (OP2) & 0.73 & $0.67^{\mathrm{b}}$ \\
My studies are the only thing that really turns me on (OP3) & 0.71 & 0.30 \\
If I could, I would only do my studies (OP4) & 0.58 & 0.85 \\
My studies are so exciting that I sometimes lose control over them (OP5) & 0.84 & \\
I have the impression that my studies control me (OP6) & 0.39 & \\
Factor correlations & & \\
HP \& OP & 0.43 & \\
\hline
\end{tabular}

$H P$ harmonious passion, $O P$ obsessive passion, Uniq uniqueness.

a Correlated uniqueness between HP1 and HP6: 0.51 .

b Correlated uniqueness between OP3 and OP4: 0.41 . 
invariance. A total of 1976 French Canadians (984 men, 630 women, 362 unspecified; $M$ age $=24.36, S D$ age $=6.68$ ) were selected as a comparison group for the Western culture group. Four models were successively tested for the invariance of parameters (factor loadings, factor variances, and factor covariances). Because $\chi^{2}$ is largely affected by sample size, in the present study, the recommended approach was to evaluate the changes in TLI and RMSEA for each model (see Marsh et al. 2013). Specifically, if the decrease in fit for the more parsimonious model is less than 0.01 for TLI, then there is a reasonable support for the more parsimonious model. The TLI is particularly relevant to model comparisons because it includes a control for parsimony comparisons (Marsh et al. 2005, 2013). Regarding the RMSEA, there is support for the more constrained model when it increases by less than 0.015 (Cheung and Renvold 2001).

Findings supported the invariance of the proposed model with respect to the Eastern and Western cultures (see Table 2). Precisely, the addition of each set of invariance constraints resulted in almost no changes in the goodness of fit. The TLI and RMSEA indices were 0.908 and 0.076 , respectively, for the unconstrained model (no invariance), 0.898 and 0.080 for the configural invariance $(\triangle \mathrm{TLI}=0.001, \triangle \mathrm{RMSEA}=0.004), 0.898$ and 0.080 for metric invariance $(\Delta \mathrm{TLI}=0.010, \triangle \mathrm{RMSEA}=0.004)$, and 0.900 and 0.079 for scalar invariance $(\Delta \mathrm{TLI}=0.008, \Delta \mathrm{RMSEA}=0.003)$.Thus, overall, there was strong support for the two-factor structure of the Passion scale in Chinese and this version was equivalent to the French-Canadian version reported in the Marsh et al. (2013) article.

\section{Convergent and Divergent Validity of the Chinese Passion Scale}

The convergent validity of the Chinese Passion Scale was examined through the correlations between HP and OP on the one hand and the five passion criteria on the other. In line with the theoretical assumptions and previous findings (Marsh et al. 2013; Vallerand et al. 2003, Study 1), it was expected that all correlations between both HP and OP and the five criteria would be positive. The hypotheses were supported (see Table 3).

The divergent validity of the Chinese Passion Scale was tested by assessing the discriminative pattern of correlations between the HP and OP subscales on the one hand and the Flow and PANAS subscales on the other. It was expected that HP would be positively related to both flow and positive emotions, but negatively related to or unrelated to negative emotions. Conversely, OP was expected to be negatively related or unrelated to flow and positive emotions, but positively related to negative emotions. The results mainly supported the hypotheses (see Table 4). First, as expected, HP was positively

Table 2 Multiple group tests of measurement invariance between Eastern and Western cultures

\begin{tabular}{|c|c|c|c|c|c|}
\hline \multirow[t]{2}{*}{ Model } & \multicolumn{5}{|c|}{ Culture invariance } \\
\hline & $d f$ & $x^{2}$ & CFI & TLI & RMSEA $(90 \% \mathrm{Cl})$ \\
\hline Model 1: no invariance & 120 & 883.221 & 0.916 & 0.908 & $0.076(0.071-0.080)$ \\
\hline Model 2: configural (FL) & 128 & $1,032.200$ & 0.901 & 0.898 & $0.080(0.075-0.084)$ \\
\hline Model 3: metric (FL + FV) & 130 & $1,050.835$ & 0.899 & 0.898 & $0.081(0.075-0.084)$ \\
\hline Model 4: scalar (FL + FV + FC) & 132 & $1,048.313$ & 0.900 & 0.900 & $0.079(0.075-0.084)$ \\
\hline
\end{tabular}

The sets of parameters constrained to be invariant across the multiple groups are combinations of factor loadings (FL), factor variances (FV), and factor covariances (FC).

CFI comparative fit index, TLITucker-Lewis index, RMSEA root-mean square error of approximation, Cl confidence interval. 
Table 3 Pearson correlations between HP and OP and the Passion criteria

\begin{tabular}{lll}
\hline Passion criteria & HP & OP \\
\hline Time spent on the activity & $0.32^{* *}$ & $0.35^{* *}$ \\
Liking the activity & $0.62^{* *}$ & $0.38^{* *}$ \\
Valuing the activity & $0.44^{* *}$ & $0.13^{*}$ \\
Passion (the activity is a...) & $0.57^{* *}$ & $0.55^{* *}$ \\
ldentity (the activity is part of my...) & $0.48^{* *}$ & $0.25^{* *}$ \\
\hline
\end{tabular}

$H P$ harmonious passion, $O P$ obsessive passion.

${ }^{*} p<.05 ; * *<.01$, two tailed.

Table 4 Pearson correlations between passion and outcomes

\begin{tabular}{lcc}
\hline Variable & HP & OP \\
\hline Flow & $0.39^{* *}$ & $0.12^{*}$ \\
Positive emotions & $0.63^{* *}$ & $0.38^{* *}$ \\
Negative emotions & $-0.14^{*}$ & $0.28^{* *}$ \\
\hline
\end{tabular}

$H P$ harmonious passion, $O P$ obsessive passion.

${ }^{*} p<0.05 ;{ }^{* *} p<0.01$, two tailed.

related to both flow and positive emotions but negatively related to negative emotions. Second, also as expected, OP was positively related to negative emotions. Finally, correlations between OP and positive emotions and flow were both positive. However, it should be noted that as expected, OP was significantly less positively related than HP to both positive emotions and flow. Furthermore, the relationship between OP and flow became non significant after controlling for $\mathrm{HP}(\operatorname{Pr}=0.09$, ns). Such was not the case for positive emotions $(\operatorname{Pr}=0.37, p<0.001)$.

\section{Discussion}

The purpose of the present research was to validate the refined version of the Passion Scale (Marsh et al. 2013) in Chinese. Specifically, (1) the two-factor structure of the scale was examined with CFA, (2) measurement invariance was assessed using multiple-group tests of invariance, and the (3) convergent and (4) divergent validity were tested. Findings provided support for the two-factor solution of the Chinese Passion Scale, for its equivalence, and for both convergent and divergent validity. Results are discussed more thoroughly below.

In line with previous research (e.g., Carbonneau et al. 2008; Gousse-Lessard et al. 2013; Marsh et al. 2013; Vallerand 2010, 2015), the CFA supported the two-factor structure of the Chinese Passion Scale. Furthermore, the internal consistency of both HP and OP subscales was high enough, suggesting that both subscales are reliable. The reliability estimates obtained in the present research replicated the findings of previous studies (e.g., Marsh et al. 2013; Ratelle et al. 2013; Stenseng 2008; Vallerand et al. 2003). Findings also provided support for equivalence of the Chinese Passion Scale when compared to a Western culture group.

In addition, convergent validity was supported by the positive correlations between $\mathrm{HP}$ and OP on the one hand and all passion criteria on the other, suggesting that both types of passion indeed reflect the construct of passion. Of interest is the fact that HP was correlated with liking, valuing, and identity significantly more highly than OP. These 
findings replicated in part those obtained in previous research (Marsh et al. 2013; Vallerand et al. 2003, Study 1).

Finally, the present results also provided support for the divergent validity of the Passion Scale. In line with previous findings, HP was positively correlated with flow, while OP was unrelated to it after controlling the influence of HP (e.g., Forest et al. 2011; Forest et al. 2008; Lavigne et al. 2012, Study 1; Philippe et al. 2009, Study 1; Vallerand et al. 2003, Study 1; Wang et al. 2011). Furthermore, in line with past research, HP was significantly positively correlated with positive emotions (e.g., Philippe et al. 2009, Study 1; Philippe et al. 2010; Vallerand et al. 2006) but negatively correlated with negative emotions (Carbonneau et al. 2010, Study 1; Young et al. 2014). Conversely, OP was significantly positively correlated to negative emotions (e.g., Carbonneau et al. 2010, Study 1; Vallerand et al. 2003, Study 1; Young et al. 2014). As expected, although OP was positively correlated with positive emotions, the correlation was significantly lower than that involving HP. This pattern of results has also been found in some studies (e.g., Lafrenière et al. 2009).

The present research could be improved in several ways. First, the questionnaire was conducted with an online survey. Individuals who were willing to answer the questionnaire may have shared some characteristics that may have influenced the results. Thus, this research should be replicated with other samples from the Chinese culture. Second, convergent validity was tested using single items and only flow and positive and negative emotions were used to assess divergent validity. Future research should replicate findings using a greater variety of measures. Third, social desirability was not examined in the present research due to the length of the questionnaire. Although previous research has shown that the Passion Scale was unrelated to social desirability (Rousseau et al. 2002), there might be differences between samples and possibly culture. Future research should test this possibility within the Chinese culture.

\section{Conclusion}

In summary, the present findings provide support for the validity and reliability of the Passion Scale in Chinese. Although the present results need to be replicated with other Chinese samples, these findings reveal that the Passion Scale in Chinese would appear to represent a psychometrically sound scale that can be used in future research with Chinese participants.

\section{Endnote}

${ }^{a}$ An Exploratory Factor Analysis using the Maximum Likelihood solution was conducted with the 12 items from the Passion Scale. Results revealed a two-factor solution with eigenvalues of 4.69 and 2.39, explaining $59.05 \%$ of the variance. An Oblimin factor rotation revealed the presence of the 6 harmonious passion relevant items on the first factor and the 6 obsessive passion related items on the second factor.

Author Details

1 Department of Psychology, Sun Yat-Sen University, 132 Daxuecheng Outer Ring East Rd, Panyu Guangzhou, Guangdong 510006, China. ${ }^{2}$ Département de psychologie, Université du Québec à Montréal, Succursale Centre-Ville, Case postale 8888, Montréal, QC H3C 3P8, Canada.

\section{Appendix}

See Table 5. 
Table 5 English and Chinese versions of the Passion Scale for studies and the passion criteria

\begin{tabular}{|c|c|}
\hline $\begin{array}{l}\text { 1. My studies are in harmony with the other activities } \\
\text { in my life }\end{array}$ & $\begin{array}{l}\text { 1. 我的学业活动和我生活中的其他所有活动是和谐 } \\
\text { 共存的 }\end{array}$ \\
\hline $\begin{array}{l}\text { 2.I have difficulties controlling my urge to engage in } \\
\text { my studies }\end{array}$ & 2. 我难以控制自己进行学业活动的冲动 \\
\hline $\begin{array}{l}\text { 3. The new things that I discover with my studies allow } \\
\text { me to appreciate them even more }\end{array}$ & $\begin{array}{l}\text { 3. 我在学业活动中发现的新事物让我更喜欢自己 } \\
\text { 的学业 }\end{array}$ \\
\hline 4. I have almost an obsessive feeling for my studies & 4. 我对我的学业活动有种近乎痴迷的感觉 \\
\hline 5. My studies reflect the qualities I like about myself & 5. 我的学业活动反映了我喜欢的自身品质 \\
\hline 6. My studies allow me to live a variety of experiences & 6. 我的学业活动让我能经历多样的体验 \\
\hline 7. My studies are the only thing that really turns me on & 7. 我的学业活动是唯一一件真正令我兴奋的事情 \\
\hline 8. My studies are well integrated in my life & 8. 我的学业活动很好地融入了我的生活 \\
\hline 9. If I could, I would only engage in my studies & 9. 如果可以，我会只进行我的学业活动 \\
\hline $\begin{array}{l}\text { 10. My studies are in harmony with other things that } \\
\text { are part of me }\end{array}$ & 10. 我的学业活动和我生活的其他部分是和谐共存的 \\
\hline $\begin{array}{l}\text { 11. My studies are so exciting that I sometimes lose } \\
\text { control over it }\end{array}$ & $\begin{array}{l}\text { 11. 我的学业活动是如此激动人心，以至于我有时候 } \\
\text { 对它失去控制 }\end{array}$ \\
\hline $\begin{array}{l}\text { 12. I have the impression that my studies control me } \\
\text { The passion criteria }\end{array}$ & 12. 我有一种我的学业活动在控制着我的感觉 \\
\hline 13. I spend a lot of time engaging in my studies. & 13. 我用大量时间来进行我的学业活动 \\
\hline 14. I like my studies. & 14. 我喜欢我的学业活动 \\
\hline 15. My studies are important for me. & 15. 我的学业活动对我来说是重要的 \\
\hline 16. My studies are a passion for me. & 16. 我的学业活动是我的激情所在 \\
\hline 17. My studies are part of who I am. & 17. 我的学业活动构成了“我是谁”的 \\
\hline
\end{tabular}

Received: 20 October 2014 Accepted: 7 July 2015

Published online: 24 July 2015

\section{References}

Burke, R. J., Astakhova, M. N., \& Hang, H. (2014). Work passion through the lens of culture: Harmonious work passion, obsessive work passion, and work outcomes in Russia and China. Journal of Business and Psychology, 29, 1-15.

Carbonneau, N., Vallerand, R. J., Fernet, C., \& Guay, F. (2008). The role of passion for teaching in intra and interpersonal outcomes. Journal of Educational Psychology, 100, 977-987.

Carbonneau, N., Vallerand, R. J., \& Massicotte, S. (2010). Is the practice of yoga associated with positive outcomes? The role of passion. The Journal of Positive Psychology, 5, 452-465.

Cheung, G. W., \& Rensvold, R. B. (2001). The effects of model parsimony and sampling error on the fit of structural equation models. Organizational Research Methods, 4, 236-264. doi:10.1177/109442810143004.

Deci, E. L., Eghrari, H., Patrick, B. C., \& Leone, D. R. (1994). Facilitating internalization: The self-determination theory perspective. Journal of Personality, 62, 119-142.

Deci, E. L., \& Ryan, R. M. (2000). The "what" and "why" of goal pursuits: Human needs and the self-determination of behavior. Psychological Inquiry, 11, 227-268.

Forest, J., Mageau, G. A., Sarrazin, C., \& Morin, E. M. (2011). "Work is my passion": The different affective, behavioural, and cognitive consequences of harmonious and obsessive passion toward work. Canadian Journal of Administrative Sciences, 28, 17-30.

Forest, J., Sarrazin, C., Morin, E. M., Brunet, L., Savoie, A., \& Mageau, G. A. (2008). La passion harmonieuse et la passion obsessive comme variables prévisionnelles de la santé psychologique et de l'état psychologique optimal de flow au travail: Résultats d'une étude empirique réalisée auprès de 118 travailleurs québécois (Harmonious and obsessive passion as predictors of mental health and the optimal psychological state of flow at work: Results from an empirical study with 118 Quebec workers). In A. Balikdjian, C. Lemoine, N. Kridis, \& P. Salengros (Eds.), Actes du colloque du 14eme congrès de l'Association Internationale de Psychologie du Travail de Langue Française (pp. 43-54). Paris: L'Harmattan.

Gousse-Lessard, A. S., Vallerand, R. J., Carbonneau, N., \& Lafrenière, M. A. K. (2013). The role of passion in mainstream and radical behaviors: A look at environmental activism. Journal of Environmental Psychology, 35, 18-29.

Hodgins, H. S., \& Knee, C. R. (2002). The integrating self and conscious experience. In E. Deci \& R. Ryan (Eds.), Handbook of self-determination research (pp. 87-100). Rochester: University of Rochester Press. 
Jackson, S. A., \& Eklund, R. C. (2002). Assessing flow in physical activity: The Flow State Scale-2 and Dispositional Flow Scale-2. Journal of Sport \& Exercise Psychology, 24, 133-150.

Jackson, S. A., \& Marsh, H. W. (1996). Development and validation of a scale to measure optimal experience: The Flow State Scale. Journal of Sport and Exercise Psychology, 18, 17-35.

Jackson, S. A., Martin, A. J., \& Eklund, R. C. (2008). Long and short measures of flow: The construct validity of the FSS-2, DFS-2, and new brief counterparts. Journal of Sport \& Exercise Psychology, 30, 561-587.

Lafrenière, M. A. K., Vallerand, R. J., Donahue, E. G., \& Lavigne, G. L. (2009). On the costs and benefits of gaming: The role of passion. CyberPsychology \& Behavior, 12, 285-290.

Lavigne, G. L., Forest, J., \& Crevier-Braud, L. (2012). Passion at work and burnout: A two-study test of the mediating role of flow experiences. European Journal of Work and Organizational Psychology, 21, 518-546.

Liu, D., Chen, X. P., \& Yao, X. (2011). From autonomy to creativity: a multilevel investigation of the mediating role of harmonious passion. Journal of Applied Psychology, 96, 294.

Marsh, H. W., Hau, K. T., \& Grayson, D. (2005). Goodness of fit in structural equation models. In A. Maydeu-Olivares, \& J. J. McArdle (Eds.), Multivariate applications book series (pp. 275-340). Mahwah, NJ, US: Lawrence Erlbaum Associates Publishers.

Marsh, H. W., Vallerand, R. J., Lafrenière, M. A. K., Parker, P., Morin, A. J., Carbonneau, N., et al. (2013). Passion: Does one scale fit all? Construct validity of two-factor passion scale and psychometric invariance over different activities and languages. Psychological Assessment, 25, 796-809.

Muthén, L.K., \& Muthén, B.O. (2008-2011). Mplus user's guide. Los Angeles: Muthén \& Muthén.

Orgambídez-Ramos, A., Borrego-Alés, Y., \& Gonçalves, G. (2014). Passionate workers: A Spanish adaptation of the Passion Scale. Revista de Psicología del Trabajo y de las Organizaciones, 30, 43-48.

Philippe, F. L., Vallerand, R. J., Andrianarisoa, J., \& Brunel, P. (2009). Passion in referees: Examining their affective and cognitive experiences in sport situations. Journal of Sport and Exercise Psychology, 31, 1-21.

Philippe, F. L., Vallerand, R. J., Houlfort, N., Lavigne, G., \& Donahue, E. G. (2010). Passion for an activity and quality of interpersonal relationships: The mediating role of emotions. Journal of Personality and Social Psychology, 98, 917-932.

Ratelle, C. F., Carbonneau, N., Vallerand, R. J., \& Mageau, G. (2013). Passion in the romantic sphere: A look at relational outcomes. Motivation and Emotion, 37, 106-120.

Rousseau, F. L., Vallerand, R. J., Ratelle, C. F., Mageau, G. A., \& Provencher, P. (2002). Passion and gambling: On the validation of the Gambling Passion Scale (GPS). Journal of Gambling Studies, 18, 45-66.

Stenseng, F. (2008). The two faces of leisure activity engagement: Harmonious and obsessive passion in relation to intrapersonal conflict and life domain outcomes. Leisure Sciences, 30, 465-481.

Stoeber, J., Harvey, M., Ward, J. A., \& Childs, J. H. (2011). Passion, craving, and affect in online gaming: Predicting how gamers feel when playing and when prevented from playing. Personality and Individual Differences, 51, 991-995.

Vallerand, R. J. (1989). Vers une méthodologie de validation trans-culturelle de questionnaires psychologiques: Implications pour la recherche en langue française (Toward a methodology of cross-cultural validation of psychological questionnaires: Implications for research in the French language). Canadian Psychology/Psychologie Canadienne, 30 662-678.

Vallerand, R. J. (2008). On the psychology of passion: In search of what makes people's lives most worth living. Canadian Psychology/Psychologie Canadienne, 49, 1-13.

Vallerand, R. J. (2010). On passion for life activities: The dualistic model of passion. Advances in Experimental Social Psychology, 42, 97-193.

Vallerand, R. J. (2015). The psychology of passion: On the Dualistic Model of Passion. New York: Oxford University Press.

Vallerand, R. J., Blanchard, C. M., Mageau, G. A., Koestner, R., Ratelle, C., Léonard, M., et al. (2003). Les passions de l'âme: On obsessive and harmonious passion. Journal of Personality and Social Psychology, 85, 756-776.

Vallerand, R. J., Rousseau, F. L., Grouzet, F. M., Dumais, A., Grenier, S., \& Blanchard, C. M. (2006). Passion in sport: A look at determinants and affective experiences. Journal of Sport and Exercise Psychology, 28, 454-478.

Vallerand, R. J., Salvy, S. J., Mageau, G. A., Elliot, A. J., Denis, P., Grouzet, F. M. E., et al. (2007). On the role of passion in performance. Journal of Personality, 75, 505-534.

Wang, C. C., \& Chu, Y. S. (2007). Harmonious passion and obsessive passion in playing online games. Social Behavior and Personality: An international journal, 35, 997-1006.

Wang, C. K. J., Liu, W. C., Chye, S., \& Chatzisarantis, N. L. (2011). Understanding motivation in internet gaming among Singaporean youth: The role of passion. Computers in Human Behavior, 27, 1179-1184.

Young, B. W., de Jong, G. C., \& Medic, N. (2015). Examining relationships between passion types, conflict and negative outcomes in masters athletes. International Journal of Sport and Exercise Psychology, 13, 132-149.

刘微娜. (2010). 简化状态流畅量表. 体育科学, 30, 6 .

邱林，郑雪，王雁飞. (2008). 积极情感消极情感量表 (PANAS) 的修订.应用心理学. Chinese Journal of Applied Psychology， $14,249-254$. 